\title{
Os objetos e o tratamento da criança autista
}

\author{
Ariana Lucero, Angela Vorcaro \\ Universidade Federal de Minas Gerais, Belo Horizonte, MG, Brasil
}

Resumo

\begin{abstract}
O objetivo deste artigo é refletir sobre o uso dos objetos na direção de tratamento psicanalítico da criança autista. Primeiramente, teceremos algumas considerações a respeito da importância do objeto na constituição subjetiva, a partir da oposição freudiana entre os princípios de prazer e de realidade. A seguir, retomaremos as considerações de Frances Tustin sobre o objeto autístico e o caso Joey, de Bruno Bettelheim, para exemplificarmos como autores clássicos da psicanálise teorizaram sobre o objeto no tratamento. Por fim, discutiremos com autores contemporâneos a importância de uma retomada da noção de objeto no âmbito da teoria e da prática psicanaliticas.
\end{abstract}

Palavras-chave: autismo; constituição subjetiva; tratamento; objeto; psicanálise.

\section{Objects and the treatment of autistic infants}

\begin{abstract}
The purpose of this article is to reflect on the use of objects in the direction of the psychoanalytical treatment of autistic infants. Firstly, from the Freudian opposition between pleasure and reality principles, we will make some considerations regarding the importance of the object in the subjective constitution. Next, we will reappraise Frances Tustin's formulations on the autistic object as well as Bruno Bettelheim's Joey case, in order to illustrate how these authors envisage the use of objects in the clinical setting. Finally, we will debate with contemporary authors the importance of a resumption of the notion of object in the scope of both psychoanalytical theory and practice.
\end{abstract}

Keywords: autism; subjective constitution; treatment; object; psychoanalysis.

O objetivo deste artigo é refletir sobre o uso dos objetos no tratamento psicanalítico da criança autista, na medida em que a relação com os objetos da realidade participa da constituição subjetiva de todo ser humano e é um instrumento importante para o diagnóstico diferencial de psicopatologias precoces graves, como o autismo.

Atualmente, "a maior parte dos clínicos e dos educadores estão de acordo em considerar que a criança autista tem necessidade de apoiar seu pensamento em elementos concretos que lhe permitam organizálo progressivamente" (MALEVAL, 2009b, p. 225). Freud (1976 [1908], p. 149-150, grifo nosso) mesmo já havia notado que toda criança necessita de "referentes materiais" para criar suas fantasias, de modo que elas atuam em suas brincadeiras o que os poetas têm a capacidade de fazer apenas com a sua imaginação:

A antítese de brincar não é o que é sério, mas o que é real. Apesar de toda a emoção com que a criança catexiza seu mundo de brinquedo, ela o distingue perfeitamente da realidade, e gosta de ligar seus objetos e situações imaginados às coisas visíveis e tangíveis do mundo real. Essa conexão é tudo o que diferencia o 'brincar' infantil do 'fantasiar'.

Se a citação acima nos esclarece a respeito da diferença entre o brincar e o fantasiar, a decrescente importância da concretude dos objetos para o brincar/ fantasiar das crianças aparece na seguinte passagem: "a criança em crescimento, quando pára de brincar, só abdica do elo com os objetos reais; em vez de brincar, ela agora fantasia. Constrói castelos no ar e cria o que chamamos de devaneios" (FREUD, 1976 [1908], p. 151, grifo nosso).

\footnotetext{
^Endereço para correspondência: Universidade Federal de Minas Gerais, Faculdade de Filosofia e Ciências Humanas, Departamento de Psicologia. Avenida Antônio Carlos 6627 - Pampulha. CEP: 31270-901. Belo Horizonte, MG - Brasil.E-mail: luceroariana@yahoo.com.br, angelavorcaro@uol.com.br
}

Na clínica com crianças em geral, o uso de objetos concretos impõe-se como condição para a circulação da cadeia significante e a importância do brincar na literatura psicanalítica sobre a infância nunca deixa de ser lembrada. Nos relatos de casos de crianças autistas, mesmo que seja comum existir um determinado objeto que se destaca na relação deste sujeito com os outros e com a própria realidade, ${ }^{1}$ a ausência do brincar parece obliterar os usos que podem ser feitos deste objeto no tratamento psicanalítico do autismo. Nesse aspecto, não podemos esquecer dos trabalhos de Frances Tustin a respeito do objeto autístico e do caso de Joey, de Bruno Bettelheim (1987 [1967]).

Porém, antes de passarmos às especificidades da criança autista, façamos uma explicação da importância do objeto para a constituição subjetiva de um modo geral, pois essa discussão permitirá que, ao final do artigo, possamos dialogar com autores contemporâneos.

\section{$O$ autista e a realidade}

A característica mais marcante do autismo é a ausência de relações sociais. A criança autista tem dificuldade em interagir com outras crianças e até com seus parentes mais próximos, o que leva muitos observadores da primeira infância a dizerem que os autistas se fecham em si mesmos, sem se importarem com a realidade que os cerca. Essa afirmação aparentemente simples, do ponto de vista da psicanálise, coloca muitas interrogações: afinal, os autistas têm um "si mesmo", um "eu" constituído

\footnotetext{
${ }^{1}$ Desde as primeiras descrições do autismo no âmbito da psicopatologia infantil, Léo Kanner (1943, online) já destacava um tipo particular de relação do autista com os objetos: "Objetos que não mudam de aparência e posição, que conversam sua mesmice e nunca ameaçam interferir na solidão da criança, são prontamente aceitos pela criança autista. Ela tem uma boa relação com objetos; interessa-se por eles, pode brincar com os mesmos por horas seguidas".
} 
dentro do qual eles se fecham?; há uma realidade interna que pode existir independentemente de uma realidade externa?; como se estabelecem os limites entre o sujeito e o mundo nos primórdios da constituição subjetiva?

Em seu Projeto de uma psicologia, Freud (1995[1895]) tece algumas considerações a respeito da diferenciação entre mundo interno e mundo externo, a partir da "vivência de satisfação", que gostaríamos de resgatar, na medida em que essa experiência funda um tipo de funcionamento psíquico regido pelo princípio de prazer.

Primeiramente, o bebê sente fome e a resposta do organismo se dirige a um esforço de eliminação, que se verifica na forma do grito ou do choro. A insuficiência dessas respostas torna necessário uma ação específica para apaziguar esse bebê: a provisão de alimento, no caso da fome, que exige uma intervenção do mundo externo.

O organismo humano é, a princípio, incapaz de promover essa ação específica. Ela se efetua por ajuda alheia, quando a atenção de um outro é atraída pelo grito do bebê. A descarga motora, ocasionada pela alteração interna, é originariamente a única via de eliminação possível. O grito adquire, assim, a função de comunicação, na medida em que um outro ser humano pode interpretálo como apelo e como demanda a ser respondida.

Quando a ação específica se efetiva, temos uma associação entre a emergência da tensão e o objeto que proporcionou a satisfação, de tal forma que pelos trilhamentos estabelecidos no sistema psíquico, o bebê pode alucinar sua satisfação sempre que sentir fome, para retomar nosso exemplo. Nesse ponto de nossa argumentação, iremos mobilizar a interpretação winnicottiana para a alucinação primordial, no intuito de contrapô-la à nossa própria leitura que, veremos, tende a acompanhar a proposta lacaniana.

Para Winnicott (1975 [1951], p. 26), a mãe dá o seio, e sua adaptação às necessidades do bebê dá a ele a ilusão de que existe uma realidade externa correspondente à sua própria capacidade de criar: "A mãe coloca o seio real exatamente onde o bebê está pronto para criá-lo, e no momento exato". Ocorre uma sobreposição entre o que a mãe supre e o que a criança poderia conceber. O bebê percebe o seio apenas na medida em que um seio poderia ser criado ali e naquele momento. Na medida em que esta experiência se repete, as ideias do bebê são enriquecidas por detalhes reais da visão e do odor, de forma que estes elementos serão acrescidos à próxima alucinação. De maneira gradual, o bebê começa a construir uma capacidade de evocar o que está realmente disponível e é assim que, segundo o psicanalista inglês, se efetiva a percepção da realidade.

Se desdobramos as afirmações freudianas do projeto, podemos dizer que, a partir do momento em que o bebê não é saciado pela recordação, ele chora e algo na realidade é acionado por essa manifestação: alguém aparece com um objeto qualquer capaz de acalmar o bebê. Esse objeto pode ser o seio, o leite, uma chupeta, a mamadeira, mas, o que se verifica, é que o bebê pára de chorar. Podemos supor que, a princípio, o bebê não pode localizar a origem deste objeto: ele vem de dentro dele, de sua lembrança, ou vem de fora, da realidade? Será necessário que o objeto falte para que o bebê possa se interrogar sobre as maneiras de obtê-lo.

O objeto, cumprindo sua função de diminuir a tensão, é um objeto que obedece ao princípio de prazer. Quanto a isso, não há dúvidas: o objeto é capaz de proporcionar prazer, ainda que não satisfaça a uma necessidade; se o bebê estiver com fome e lhe derem uma chupeta, ele irá parar de chorar ainda que temporariamente. Aquilo que aparentemente era da ordem da necessidade, a fome, é subvertido por um outro que introduz no funcionamento do organismo algo que escapa à ordem natural. Aliás, Lacan (1995[1956-1957], p. 178) consegue demonstrar como o objeto que "naturalmente" satisfaria a necessidade, o seio que alimenta, só ganha importância para a criança quando pode ser associado à presença da mãe, de modo que ele já aparece associado a uma falta:

é na medida em que a mãe falta à criança que a chama que esta se agarra ao seu seio, e que este seio se torna mais significativo que tudo. Enquanto o tem na boca e se satisfaz com ele, por um lado a criança não pode ser separada da mãe, por outro lado isso a deixa alimentada, repousada e satisfeita.

Retomando a leitura freudiana, cabe destacar que inicialmente o bebê busca apenas a diminuição da tensão - princípio de prazer - proporcionada por um objeto qualquer. Vejamos a explicação que Moustapha Safouan (1988, p. 28, grifo nosso) nos fornece a respeito deste funcionamento "alucinatório" e regido pelo princípio de prazer do psiquismo do ser humano:

a pressão das necessidades conduz não a pensar a coisa, (seja ela o seio ou o Nebenmensch) que restabelecia o repouso, ou a desejá-la, mas sim a crer percebê-la, dito de outro modo, a aluciná-la. Lidamos, então, não apenas com um organismo pouco preparado para a vida, como o admitiria qualquer biólogo e qualquer observador da primeira infância, mas ainda, e sobretudo, com um psiquismo positivamente dotado de um princípio contrário às exigências da vida como tal, porquanto esta requer uma adesão mínima aos sinais ou, se quisermos, aos logros do Umwelt. No momento o qual supomos que o aparelho psíquico não se contenta em pensar o que quer, mas "realiza" seu pensamento antes de reconhecê-lo no real, colocamos, ao mesmo tempo, que esse aparelho existe em uma adesão principal às suas próprias ficções ou aos seus próprios logros; um aparelho, em suma, que não tem necessidade de se opor para se pôr, um aparelho que não espera, que não espera nem mesmo que a realidade o decepcione antes de substituí-la alucinatoriamente por uma outra realidade [...].

Se o aparelho psíquico é movido pela associação a um objeto que teria proporcionado uma primeira e única experiência de satisfação, e se esse objeto não pode ser recuperado - até porque ele nunca existiu dessa forma plena na realidade, sendo, na melhor das hipóteses, um objeto qualquer -, resta ao sujeito contentar-se com o prazer advindo de outros objetos.

Lacan (1979[1964], p. 180) alerta os psicanalistas para o fato de que o lactente se interessa por tudo o que entra em seu campo de percepção, em especial, os 
objetos: "que haja objetos desde o tempo mais precoce da fase neonatal é o de que não há a menor dúvida. Autoerotisch não pode absolutamente ter o sentido de desinteresse em relação a eles".

Para Lacan (1979 [1964], p. 227), “a regra do auto-erotismo não é a inexistência dos objetos, mas o funcionamento dos objetos unicamente em relação com o prazer". Desse modo, a percepção dos objetos coexiste com o auto-erotismo e, de certa forma, com a vivência alucinatória que tende a excluir a realidade. Isso nos leva a questionar se o neonato percebe os objetos como pertencentes à realidade ou se ele incorpora-os automaticamente ao seu funcionamento auto-erótico, regido pelo princípio de prazer.

Esta última alternativa coincide com as observações de que os autistas experimentam os objetos como partes de seu corpo, de tal forma que podem se satisfazer com os objetos da realidade auto-eroticamente. Mas isso ocorreria com todas as crianças? Estaria já aí a diferenciação entre o objeto autístico e o objeto transicional?

Trabalhamos com a hipótese de que a criança autista não interrompe o circuito pulsional alucinatório em direção ao princípio de prazer em prol do assentimento à realidade. Nesse ponto, faz-se mister três esclarecimentos: 1) o autista é afetado pela linguagem, tal como todos os seres humanos, o que inclusive faculta a possibilidade da alucinação e do auto-erotismo; 2) algo da pulsão circula pelo corpo do autista, mas há uma dificuldade em direcioná-la para o exterior, uma vez que 3) os objetos, sentidos como partes do corpo, são investidos pulsionalmente de forma auto-erótica, o que oblitera a função de intermediar a realidade, presente, por exemplo, nos objetos transicionais. Se lembrarmos do segundo dualismo pulsional freudiano, podemos dizer que há uma precariedade da pulsão de vida em operar suas ligações com o mundo externo. O predomínio da pulsão de morte, em sua função de manter as excitações no nível mais baixo, coincide com o princípio de prazer tal como descrito no Projeto, de modo que este último se refere, na verdade, a um além do princípio de prazer que, como já advertiu Lacan, só pode ser experimentado como gozo. É este gozo autístico (auto-erótico e mortífero) que deverá ser tratado para que o simbólico, o que faz laço social, enfim, o que liga o ser à realidade (à vida) possa operar. A afirmação de Lacan (2008[1968-1969], p. 220) de que "o Outro [simbólico] é justamente isso, é um terreno do qual se limpou o gozo" parece resumir bem essa nossa ideia.

De acordo com Maleval (2012, p. 49), “a segunda subtração do gozo que intervém na construção subjetiva, aquela que produz a extração dos objetos $a$, conectandoos ao falo, e aquela que lastreia o fantasma com o maisde-gozar, essa operação de separação não funciona nos autistas". No entanto, há uma primeira subtração de gozo, relacionada à incidência da linguagem em todo ser humano, e que tanto Freud quanto Lacan delimitaram sob a forma de das Ding, ${ }^{2}$ que se refere a

\footnotetext{
${ }^{2} \mathrm{Em}$ um artigo anterior (LUCERO; VORCARO, 2009), nos aprofundamos na importância do conceito de das Ding para a compreensão da constituição subjetiva na perspectiva lacaniana.
}

esse "buraco angustiante, bem diferente de uma falta dinâmica, produzido pela primeira subtração do gozo, o que evidencia um traumatismo decorrente da intervenção da linguagem" (MALEVAL, 2012, p. 49). É esse buraco que o autista tenta tapar com os objetos concretos que ele retém como parte de seu próprio corpo.

Na concepção de Eric Laurent (2007, p. 28):

no campo do espectro dos autismos, o Um de gozo não pode ser apagado; não há apagamento dessa marca do acontecimento de corpo [...] Esse não apagamento do Um marca o corpo como um corpo que goza de si mesmo, num para-além do Princípio do Prazer.

O psicanalista afirma que o corpo do autista é invadido por um pleno de gozo (LAURENT, 2009) e Maleval (2009a) parece concordar ao afirmar que as sinestesias tão comuns nos autistas resultam de um transbordamento dos limites do gozo. Para Maleval (2009a, p. 46), a extração dos objetos $a$ organiza a percepção e "quando tal extração não se opera, a construção da realidade se revela cambaleante".

Ora, mas isso quer dizer que o autista está fora da realidade? Ou que ele vive em um mundo à parte, totalmente separado de nossa realidade compartilhada? A descrição do autista como uma criança introspectiva, fechada para o mundo externo, coexiste lado a lado com a observação de que os autistas servem-se dos objetos que eles encontram em seu ambiente. Isso nos leva a concluir que o autista tem sim algum contato com o mundo externo, a realidade, mas se recusa a entrar no processo de alienação (cf. SOLER, 1997, p. 22), isto é, ele não compartilha com outros (com "o" minúsculo) os significantes do Outro. ${ }^{3}$

Deve-se salientar que o mundo do significante é animado pelo Outro, que a mãe encarna através de seu corpo e dos objetos do desejo que são o olhar e a voz (LACADÉE, 1997). Desse modo, independentemente do objeto concreto estar em jogo desde o nascimento da criança em sua relação com o Outro através da satisfação das necessidades (LACADÉE, 1997), ele pode não adquirir as propriedades do significante. ${ }^{4}$

Michel Silvestre (1997) assevera que o autista está na linguagem - disso não podemos duvidar -, mas sem a função da fala. Logo, uma abordagem possível do autismo se dará a partir de uma certa concepção de objeto (SILVESTRE, 1997). Silvestre (1997) destaca os trabalhos feitos com autistas sob a perspectiva kleiniana e interroga se, nos casos de autismo, os objetos deveriam ser pensados em termos de significantes, ou, simplesmente, tratados como objetos concretos. Vejamos as considerações de Frances Tustin acerca do objeto autístico e o caso de Joey, de Bruno Bettelheim, no intuito de melhor elucidar essa questão.

\footnotetext{
${ }^{3}$ De acordo com Safatle (2007), o Outro, com "o" maiúsculo é a maneira como o "outro" empírico pode aparecer para o sujeito. Como o Outro pode ser representado por uma figura empírica, Lacan falará, por exemplo, do Outro materno.

${ }^{4}$ Uma discussão mais aprofundada sobre o funcionamento da linguagem no autismo pode ser encontrada nos artigos de Maleval (2009a) e Barroso (2009).
} 


\section{O autista e o objeto}

A psicanalista inglesa Frances Tustin dá especial atenção à questão dos objetos quando faz o relato dos casos clínicos de seus pacientes autistas ou psicóticos. Tustin (1975[1972]) descreve o autismo como uma parada do desenvolvimento psicológico em uma fase muito primitiva ou uma regressão a tal fase. Essa definição presume que exista uma fase autística do desenvolvimento comum a todas as pessoas. Tustin (1975[1972], p. 9) a denomina "autismo da infância primitiva", caracterizando-a como uma fase em que "o bebê não percebe claramente a existência de um mundo externo, vivendo-o da mesma forma que os órgãos, processos e zonas de seu corpo".

É válido ressaltar que este corpo ainda não existe como totalidade integrada nem possui uma representação visual (o que, sabemos, só é possível a partir do estádio do espelho), mas lhe aparece como órgãos separados: mãos, boca, braços ou barriga. Para Tustin (1975[1972]), esses diversos órgãos são experimentados como "objetos totais", uma vez que o bebê os desconhece como partes relacionadas entre si.

Na concepção de Tustin (1975[1972]), o autismo patológico é caracterizado como o predomínio de sensações corporais (gozo?) em detrimento da percepção do mundo externo. As crianças autistas seriam aquelas que se fecham, se "encapsulam", para o que vem de fora e se concentram apenas em seus sentimentos. Uma das formas usadas pelos autistas para manterem essa posição - que é a que nos interessa neste trabalho e que Tustin (1975[1972]) aborda em seu livro - consiste em concentrar-se nos objetos para evitar o susto do mundo externo, tudo aquilo que é "não-eu".

Tustin (1975[1972]) define os objetos autísticos como partes do corpo da própria criança ou partes do mundo externo experimentados por ela como partes de si mesma. Ou seja, não haveria uma diferenciação entre o "eu” e o objeto "não-eu". O objeto seria uma parte do "eu" da criança. O objeto autístico é completamente experimentado como "eu" e a autora chega a diferenciá-lo do objeto transicional descrito por Winnicott, na medida em que este último conjuga em si um misto de "eu" e "não-eu” (TUSTIN, 1975[1972]). O objeto transicional é algo que a criança distingue do próprio corpo. Já o objeto autístico consiste em neutralizar toda e qualquer percepção da existência de um "não-eu". O objeto autístico visa a obscurecer a quebra de continuidade do "não-eu" (TUSTIN, 1975[1972]), isto é, visa a anular a existência do mundo externo. Ela ressalta que, quando a criança tenta transformar a mão de outra pessoa em objeto autístico, usando-a como coisa destituída de vida ou vontade própria e como extensão de si mesma, é como se não reconhecesse as outras pessoas e os outros objetos do mundo externo em geral como "não-eu".

Pois bem, a criança que usa os objetos de forma autística o faz como se eles fizessem parte de seu próprio corpo e fossem o verdadeiro objeto de seus desejos, obstruindo os sentimentos de frustração (cf. TUSTIN,
1975[1972], p. 78). A criança não brinca com os objetos autísticos, mas usa-os para repelir um sentimento de desastre. Tustin (1975[1972]) compara a função de tais objetos às propriedades de um amuleto e ressalta a preferência por objetos duros, não macios.

Para Tustin (1975[1972]), os objetos autísticos “eu" visam a manter à distância o reconhecimento do terrível e ameaçador "não-eu" e são, por isso, anormais e patológicos. A autora tem a impressão de que as crianças autistas se sentem confortáveis, satisfeitas consigo mesmas, "pseudo-auto-suficientes". Ela ressalta que podemos observar de diversas maneiras como o bebê e a criança psicótica usam os "objetos autísticos" para conseguirem esse sentimento interno de auto-suficiência (cf. TUSTIN, 1975[1972], p. 72). Dessa forma, Tustin (1975[1972]) afirmava que uma das vias do tratamento do autismo seria a retirada de tais objetos autísticos da criança. Ela acreditava que, na ausência dos objetos, a criança ficaria sem essa proteção contra o mundo externo e se tornaria mais permeável à sua influência. Além disso, Tustin (1981) conclui que os objetos autísticos são patológicos, pois resultam de um auto-erotismo excessivo que se desviou e se tornou perverso. Sua utilização visa a evitar a frustração e a desilusão da perda do seio, tamponando o furo causado pela ruptura do conjunto mamilo-boca. O uso excessivo dos objetos entrava o desenvolvimento da capacidade simbólica, quase excluindo um uso transicional e comunicativo. ${ }^{5}$

Philippe Lacadée (1997) afirma que, em um de seus últimos trabalhos, intitulado Novas visões sobre o autismo psicogenético, Frances Tustin corrige uma de suas perspectivas sobre o autismo. A partir daí, o termo autismo deve ser reservado a certos estados patológicos específicos, e não extensivo a todo desenvolvimento infantil. A autora ressalta que, desde o início da vida psíquica do bebê, há um mundo exterior (cf. LACADÉE, 1997, p. 47). Em sua nova concepção, o autismo adviria de uma separação traumática da mãe, como se esta ruptura fosse sentida como uma perda de parte do próprio corpo do bebê. Maleval (2009b, p. 226) retoma a ideia de Tustin de que os objetos autísticos funcionam como proteção contra a perda e visariam a impedir a separação corporal. De acordo com Tustin (apud MALEVAL, 2009b, p. 223), esses objetos vividos como partes do corpo

não ajudam, também, a suportar a tensão e a adiar a ação - o que é essencial para as atividades simbólicas [...] não são substitutos temporais da mãe, eles a substituem de modo permanente. Os cuidados da mãe se tornam, por isso, nulos e sem efeito.

Neste artigo, tentamos reunir as observações de Tustin que mais se aproximam das nossas considerações teóricas. É claro que o seu ponto de vista encontra substrato em seu próprio aparato teórico, mas esse é um referencial que, para nós, precisa ser esclarecido. O "eu" e o "não-eu" devem ser entendidos de acordo com Freud (2007[1925]), isto é, o "eu" como "eu-prazer" - que obedece ao princípio

${ }^{5}$ As considerações sobre o livro de Tustin, Os estados autísticos na criança, foram extraídas de Bocke e Delius (1997). 
de prazer e que, como vimos, acaba resultando no gozo - e o "não-eu" como tudo aquilo que vem de fora, que interrompe a homeostase e que o "eu" tende a expulsar.

Quanto à questão da separação mãe-bebê, Tustin, assim como Mahler (2002), acreditava que, a princípio, o bebê e a mãe formavam um só corpo e se confundiam um com o outro (simbiose). Lacan nunca aderiu a essa ideia e mesmo o processo de alienação não envolve uma imbricação de corpos, mas apenas de significantes. No entanto, se retivermos a hipótese de que os objetos autísticos funcionam como proteção contra a perda (de das Ding) e se tornam, por isso, substitutos permanentes da mãe, ${ }^{6}$ podemos tentar uma compreensão para a ausência do brincar nessas crianças.

Se pegarmos como exemplo o fort-da, na concepção lacaniana de que "o jogo do carretel é a resposta do sujeito àquilo que a ausência da mãe veio criar" (LACAN, 1979[1964], p. 63), podemos dizer que a criança autista não brinca, pois os objetos adquiriram a propriedade de substituir definitivamente a mãe e, portanto, não podem ser jogados. Os objetos não funcionam como significantes e seu papel de representação acaba por tornar-se sígnico, isto é, colado a uma única representação, no caso, a representação da mãe. Ademais, o objeto autístico, cumprindo essa função de "tapa-buraco" e tornando-se parte do corpo da criança, não pode participar do jogo de substituições necessário à circulação da cadeia significante.

Por fim, nosso último ponto de diálogo com Tustin se refere ao uso que pode ser feito do objeto no tratamento do autismo. Podemos adiantar que discordamos da autora quando diz que os objetos autísticos devem ser retirados da criança. Contudo, antes de tecermos nossas considerações, vejamos o que Bruno Bettelheim tem a nos dizer sobre esse assunto.

Bruno Bettelheim (1987[1967]) irá recontar o caso de Joey, um menino autista que, desde muito pequeno, possui uma relação peculiar com os objetos. Para isso, ele tece alguns comentários gerais sobre o objeto no autismo, enfatizando, primeiramente, que o lactente é menos capaz de manipular objetos, sobretudo os complexos, do que a criança autista (BETTELHEIM, 1987[1967]). Ou seja, o autista não é um bebê ou uma criança regredida - Bettelheim (1987[1967], p. 315-324) discute com especial atenção o uso do termo "regressão" -, mas um sujeito que encontrou uma maneira diferente de "adaptar-se" ao mundo.

Para Bettelheim (1987[1967]), a atividade manipulatória da criança autista pode revelar muito sobre o que se passa em sua intimidade, mas isso não quer dizer que ela se relaciona com objetos, em oposição a se relacionar com pessoas. Por isso, diferentemente de Tustin, o psicanalista não julga necessário privar o autista de seus objetos e conduz o tratamento de forma ${ }^{6}$ Lacan (1997[1959-1960]) nos alerta para o fato de que, no nível da interpsicologia mãe-criança, costuma-se dizer que aquilo que ocupa o lugar de das Ding na primeira experiência de satisfação descrita no Projeto é a mãe, de modo que o desejo pelo objeto é o desejo de incesto. Nesse sentido, apesar de Lacan não identificar a causa da falta com a perda do objeto materno produzida pela interdição do incesto, devemos lembrar que "o impasse do desejo [em Lacan] ganha forma no interior do drama edípico, o que não quer dizer que ele é produzido por ele" (SAFATLE, 2006, p. 87, grifo do autor). a privilegiar as relações da criança com os outros. Por outro lado, tal como Tustin, Bettelheim acredita que o comportamento das crianças autistas indica um bloqueio precoce do interesse pelo mundo externo, uma vez que elas agem preferencialmente sobre seu corpo e sobre um punhado de objetos que são manipulados, em geral, de maneira ritualística:

Às vezes, esforços interpretativos imaginários são bemsucedidos em atribuir um significado profundamente pessoal, específico a esses objetos. [...] Mas esses objetos funcionam com frequência menos como canalizadores de significado do que como preventivos contra qualquer desafio para a ação que pudesse vir do mundo. A concentração da criança autista no brinquedo infindavelmente manipulado ou na reconstituição repetida e ritualística do quebracabeças, no escutar várias vezes o mesmo disco - para além do significado de tal comportamento - também serve para impedir que os estímulos a atinjam, porque poderiam induzi-la à ação (BETTELHEIM, 1987[1967], p. 89-90).

De certa forma, Bettelheim (1987[1967]) identificava no uso dos objetos pelo autista a mesma característica de proteção contra o mundo externo que, vimos, Tustin havia destacado como perniciosa. No entanto, o exemplo de Joey interroga essa concepção.

Quando Bettelheim (1987 [1967]) viu Joey pela primeira vez, o menino tinha nove anos e meio e podia falar. Porém, quase sempre ficava quieto e praticamente não era notado até colocar em funcionamento sua máquina. De uma hora para outra, Joey parecia enfurecerse, saía correndo e gritando "Bum! Bum!", enquanto atirava uma lâmpada ou um motor para o alto. Logo que o objeto se quebrava e que o barulho acabava, Joey também "morria": "Sem qualquer transição, retornava à sua aparente não-existência. Explodida a máquina, não restava movimento, vida, absolutamente nada" (BETTELHEIM, 1987[1967], p. 255).

Joey estendia fios imaginários que o "ligavam na tomada" para realizar suas atividades (comer e excretar, p. ex.) e, normalmente, mantinha uma lâmpada em suas mãos. Aos olhos dos observadores: "Se por acaso [Joey] fazia algo, parecia funcionar por controle remoto - um 'homem mecânico' dirigido por máquinas que haviam sido criadas por ele e que lhe escapavam ao controle" (BETTELHEIM, 1987[1967], p. 254).

O menino precisava das máquinas para sobreviver e inventava aparelhagens para dormir, respirar etc. $\mathrm{Na}$ instituição em que se encontrava, todos reconheciam e respeitavam a importância de seus aparelhos e eles foram usados em prol do estabelecimento de uma comunicação e de uma relação com a criança.

Gostaríamos de destacar que o interesse de Joey por objetos, em especial por um ventilador, chamou a atenção de sua família desde quando ele tinha um ano e meio de idade (cf. BETTELHEIM, 1987[1967], p. 261). Os pais conseguem associar o ventilador às hélices do avião - em que o pai partia e retornava do serviço militar, enquanto a mãe observava de longe, junto com Joey, no aeroporto - e dizem que aos quatro anos o filho girava 
as mãos como se fossem uma hélice (BETTELHEIM, 1987[1967]). Contudo, sempre que descobria um motor ou um ventilador real, suas "hélices" imaginárias eram deixadas de lado (BETTELHEIM, 1987[1967]).

Não entraremos nos pormenores do caso de Joey, pois nosso objetivo é apenas o de mostrar como a criança complexifica sua relação com os objetos e como esses objetos, de certa forma, a mantém conectada com o mundo externo. As máquinas despertam a curiosidade de Joey e fazem com que ele possa ser visto: "Joey tinha a capacidade de prender a atenção fascinada daqueles que o observavam no seu vácuo, de os induzir a considerálo uma máquina” (BETTELHEIM, 1987[1967], p. 257). Através das máquinas, do ventilador ou de um "corpomáquina", Joey conseguia atrair o olhar dos outros para objetos que tinham relação com sua subjetividade, sem se expor demasiadamente. É difícil sabermos porque o menino teve que se proteger do Outro dessa maneira, mas Bettelheim (1987[1967]) nos deixa entrever detalhes de sua história que podem nos auxiliar nessa tarefa. Neste trabalho, importa ressaltar que, independente do que ficou para trás, talvez o simples fato dos pais terem percebido ou suposto um significado para o ventilador possa ter permitido que alguma circulação significante fosse acessível a Joey. Voltaremos a esse ponto.

\section{Considerações finais}

Ainda é comum a visão de que o objeto autístico não encadeia nada além dele mesmo, só chama por ele e finaliza em si próprio o processo da linguagem (REY-FLAUD, 2008), uma vez que os autistas não entram na demanda e se situam aquém da simbolização (SOLER, 1997). Porém, muitos autores contemporâneos questionam essa visão e apostam na importância do objeto para a construção da subjetividade da criança autista.

Jean-Louis Bonnat (2008) enfatiza a importância da pesquisa clínica em torno do objeto autístico. Bonnat (2008) nos lembra que a noção de objeto autístico apareceu nos anos 70, com Frances Tustin e afirma que as crianças autistas só podem ter seu universo subjetivo sustentado e estruturado pela presença de objetos reais. No seu modo de dizer, é como se houvesse uma necessidade de avaliar e de se apoiar sobre esse tipo de objeto dito de "suplência", de síntese, de aparelhagem, ou, simplesmente, de construção específica de uma subjetividade que mantém o Outro da fala, da enunciação, à distância (BONNAT, 2008). Na concepção de Bonnat (2008), os objetos fazem uma borda real para o corpo do sujeito privado da aparelhagem imaginária que se refere ao Outro do significante da significação fálica. Trata-se, por conseguinte, de um corpo real, material, que o sujeito não pode dissociar ou perder dele mesmo. Bonnat (2008) compara a função dos objetos autísticos com os espartilhos e com o casulo das borboletas, mas com a diferença de que o autista não pode deles se desprender. Quando tentamos tirar os objetos do autista, ele grita, esperneia e, durante muito tempo, a partir das considerações de Tustin, pensava-se fazer o certo separando o autista de seus objetos para adaptá-lo à realidade. Contudo, segundo Bonnat (2008), é apenas a partir de uma imagem real, forjada a partir dos objetos, que o autista pode estabelecer uma "troca" com os outros.

Eric Laurent (2007) também ressalta a importância dos objetos para a formação de um corpo no autista. Segundo este autor, "o objeto-fora-do-corpo integra, pouco a pouco, os deslocamentos dele decorrentes. Esse objeto é seguidamente tomado, encerrado no interior do que se tornará corpo íntimo. Será sempre a produção de uma montagem do corpo, ainda que seja um objeto forado-corpo" (LAURENT, 2007, p. 31). O objeto atua como um órgão suplementar que as crianças tentam introduzir em seu corpo como o órgão que conviria à linguagem. $\mathrm{O}$ autista mantém com este objeto uma relação de relocalização incessante, uma tentativa de situar-se. É através deste objeto que o autista pode se apegar ao Outro da linguagem (cf. LAURENT, 2007, p. 30).

Maleval (1997) afirma que a defesa autística se apóia sobre objetos e se desenvolve pelo acoplamento de significantes a esses objetos. A princípio, teríamos apenas um "objeto autístico bruto", qualquer brinquedinho com que a criança se distrai, que não porta significantes organizados, mas já pode ser utilizado pelo sujeito para pôr ordem no mundo, na medida em que ele participa do trabalho de manter a imutabilidade e elaborar a fronteira para proteger do desejo do Outro. Maleval (1997) propõe que a esses objetos quaisquer, poderiam se seguir "objetos autísticos não regulados", portadores de significantes não compartilhados por outras pessoas. O autista se encontra colado a esses objetos em estado de inércia (por exemplo, ventiladores, máquinas etc). $\mathrm{O}$ autor inclui as máquinas de Joey nesta categoria. Já os “objetos autísticos regulados" seriam os calendários, listas telefônicas, enfim, aqueles que designam os autistas savants, que respondem automaticamente, sem trabalho voluntário e de maneira quase alucinatória, às questões colocadas para testar suas aptidões excepcionais. No último degrau de elaboração da defesa autística, surge o "objeto regulador" ${ }^{7}$ Este objeto é uma realização do simbólico e porta significantes organizados. O sujeito se acha em condições de desenvolver capacidades de adaptação a situações imprevistas, apoiando-se sobre um objeto que instaura uma borda entre o sujeito e o Outro do desejo. Neste grupo, o autor inclui a "máquina elétrica" de Joey - construída após a saída da instituição e quando Joey já tinha em torno de vinte anos - e a "máquina de abraço" (ou brete) de Temple Grandin ${ }^{8}$. O artigo de Maleval (1997) é breve e, sem maiores esclarecimentos, conclui que não podemos mais sustentar com Tustin que o objetivo principal do tratamento consiste em ajudar a criança a renunciar aos artifícios falaciosos que são os objetos autíticos.

\footnotetext{
${ }^{7}$ A tradução aqui utilizada para os quatro objetos delimitados por Maleval (1997) - objeto autístico bruto, objeto autístico não regulado, objeto autístico regulado e objeto autístico regulador - foi inicialmente proposta por Paula Pimenta (2012, p. 53) em sua tese de doutorado.

${ }^{8}$ Trata-se do caso de uma autista que constrói uma aparelhagem para uso humano semelhante às máquinas que contém o gado antes do abate. Cf Grandin e Scariano (1999).
} 
Concordamos que os objetos não devem ser retirados do autista, entretanto, ao privilegiar o "objeto regulador", Maleval parece supor uma hierarquia no desenvolvimento das defesas autísticas, como se pudéssemos estabelecer um programa de tratamento. Maleval (2009a), de fato, segue esse raciocínio ao discernir três fases progressivas na relação do autista com o espelho, sem que seja possível falarmos de um estágio do espelho propriamente dito. $\mathrm{O}$ autor estabelece uma associação entre o duplo e o objeto autístico, que consideramos extremamente pertinente (apesar de implicar uma ideia de sucessão que deve ser interrogada), apoiando-se, para isso, no autorelato de Donna Williams. No entanto, ao tentar transpor suas considerações para Joey e Grandin, por exemplo, Maleval (2009a) não consegue refazer o percurso desses autistas por suas fases do espelho.

O psicanalista afirma que Grandin soube, inclusive, tirar melhor proveito de um apoio no objeto autístico do que Williams. Em seu caso, o objeto não está colado no espelho e sua "máquina de abraço", apesar de ter uma conexão com seu duplo - uma vez que ela mesma se instala na máquina na mesma posição que o gado -, não é um duplo do sujeito, servindo, isto sim, para tratar o duplo. Em relação à Joey, sua "máquina elétrica" parece ser da mesma ordem da de Grandin, uma vez que ela regula a energia que Joey precisa, mas nada indica que seja também um duplo.

Maleval (2009a, p. 431) conclui que:

quando o objeto autístico é elevado ao mais alto grau, descola-se do duplo para se articular de maneira estreita ao Outro de síntese - ele próprio desenvolvendo os pontos de competência, de tal modo que Grandin, assim como Joey, encontra no seu objeto autístico o fundamento de sua inserção profissional e social. Uma se torna especialista mundial em confinamento de gado, o outro encontra um métier na eletrônica.

Novamente aparece uma hierarquia no nível de elaboração do objeto autístico e parece que a saída encontrada por Williams fica aquém das soluções apresentadas por Joey e Grandin, apesar de ser dito que a relação de Williams com outros seres humanos sugeria uma maior proximidade do que aquela que Grandin podia suportar. Ademais, se lembrarmos das máquinas mais precárias de Joey, sabemos que elas sempre suscitaram a atenção das pessoas e permitiram a emergência de alguns significantes que podiam sim ser compartilhados. A própria mãe de Joey encontrou um sentido para sua fascinação com ventiladores e, na instituição, todos sabiam da importância de Joey estar ligado a suas máquinas para sobreviver. Já a "máquina elétrica", que realmente funcionava, foi construída por Joey após frequentar uma escola técnica e ele tinha muito orgulho dela, mostrando-a a todos que quisessem vê-la (cf. BETTELHEIM, 1987[1967], p. 367). Seu avanço em relação aos aparelhos anteriores dizia respeito à sua utilidade reconhecida por todos, sem que nenhuma significação particular precisasse ser acoplada ao seu funcionamento. Mas, talvez, para a constituição subjetiva de Joey, suas máquinas mais precárias tenham sido mais importantes.
Pimenta (2012) destaca que a classificação dos objetos autísticos em quatro tipos é posteriormente substituída por duas categorias: simples e complexos (cf. MALEVAL, 2009b). Servindo-se majoritariamente da proposta de Maleval (2009a) de construção de um duplo, a psicanalista aborda fragmentos de seus casos clínicos e o trabalho de Myriam Perrin, concluindo ser extremamente difícil atingir um objeto autístico complexo no trabalho com autistas: "por que, nos fragmentos de nossa clínica, não conseguimos referir a nenhum objeto autístico complexo elaborado pelos autistas que acompanhamos? [...] a quantidade de autistas que alcançam esse nível de elaboração é imensamente pequena" (PIMENTA, 2012, p. 196). É por isso que, focando-nos nos objetos mais simples, supomos ter resultados bastante satisfatórios, como o próprio caso de Charlie, paciente de Perrin (2009) já nos deixa entrever.

Interessa-nos, portanto, demarcar a função constitutiva dos objetos autísticos, na medida em que podem, de fato, ser tomados como partes do corpo da criança. Laurent (2012, p. 29) sugere como indicação para o tratamento do autista:

um forçamento de inclusão de um buraco para encontrar uma saída diante desse pleno de gozo que invade o corpo. Produzir um buraco, para, depois, extrair algo do corpo e colocá-lo aí e, assim, acalmar esse gozo infernal do acontecimento de corpo que invade o sujeito.

Acreditamos que esse buraco, referente à segunda extração de gozo e, portanto, ao objeto $a$ (e não à das Ding), pode ser produzido via objeto autístico, sob pena de se tornar demasiado insuportável ao sujeito. Ao centrar-se no objeto manipulado pelo autista, o analista evita o contato visual tão incômodo para essas crianças e pode falar-lhe indiretamente, ao conversar com o objeto. Conforme a criança suporte esse diálogo e esse investimento pulsional do analista no objeto, ela pode ceder à troca e um jogo pode se estabelecer. Isso pode ser feito de diversas maneiras e cabe ao clínico encontrar uma forma de se aproximar desse objeto: desenhando, forjando um semelhante para ele, tentando movimentar lhe, inventando uma história.... Aos poucos, a criança pode soltar o objeto, deixar que o analista o segure e, enfim, inseri-lo no circuito pulsional da troca, que caracteriza a extração do objeto $a$ e organiza a percepção da realidade.

Para finalizar, enfatizamos que nossa aposta no tratamento de crianças autistas, seguindo a orientação psicanalítica, consiste em privilegiar o uso dos objetos como forma de estabelecer uma relação com o sujeito. ${ }^{9}$ Se essa relação irá possibilitar uma circulação da cadeia significante, a emergência de um duplo, a formação de uma imagem corporal, a criação de um objeto de suplência, todas essas saídas devem ser consideradas, desde que respeitem a singularidade do sujeito. Nesse sentido, a despeito de algumas discordâncias com Maleval (2009a, p. 418) convém concluir com o psicanalista que, se por muito tempo:

9 A pesquisa "O uso de objetos na direção do tratamento psicanalítico da criança autista", a ser realizada na Universidade Federal do Espírito Santo, com o apoio da FAPES/CAPES, visa a se aprofundar nessa proposta de tratamento. 
no horizonte de todas as abordagens educativas, [foi considerado] como uma evidência que, para ajudar o autista, convém "tratar o apego não-adaptado aos objetos ou a adesão inflexível às rotinas quotidianas" (Hemsley et al., 1978, p. 479) ${ }^{10}$, uma abordagem orientada pela psicanálise leva a desconfiar desses pressupostos - antes de mais nada, por razões éticas; mas também porque eles não levam em conta o trabalho de proteção contra a angústia em operação nessas condutas.

Acreditamos que a principal conduta no atendimento psicanalítico às crianças autistas é fazer valer no tratamento as defesas que o sujeito foi capaz de estruturar, pois isto é o próprio sujeito, o que lhe é mais singular.

\section{Referências}

BARROSO, S. O autista, mestre da linguagem. In: MURTA, A.; CALMON, A.; ROSA, M. (Org.). Autismo(s) e atualidade: uma leitura lacaniana. Belo Horizonte: Scriptum, 2009. p. 135149.

BETTELHEIM, B. A fortaleza vazia (1967). São Paulo: Martins Fontes, 1987.

BOCKE, K.; DELIUS, M. L'enfant autiste et sa mère au pays de Mahler et Tustin. Bulletin du Groupe Petite Enfance, n. 10, p. 130-135, 1997.

BONNAT, J.-L. (Org.). La machine autistique: fonctions. In: Autisme et psychose: machine autistique et délire machinique. Rennes, FR: Presses Universitaires de Rennes, 2008. p. 191-201.

FREUD, S. Escritores criativos e devaneio (1908). In: SALOMÃO, J. (Org.). Obras Psicológicas Completas de Sigmund Freud. Rio de Janeiro: Imago, 1976. v. 9, p. 147-158. Edição Standard Brasileira.

FREUD, S. Projeto de uma psicologia (1895). Tradução de Osmyr Gabbi Jr. Rio de Janeiro: Imago, 1995.

FREUD, S. A Negativa (1925). In: Escritos sobre a Psicologia do Inconsciente. Tradução de: Luiz Hanns. Rio de Janeiro: Imago, 2007. v. 3, p. 145-157.

GRANDIN, T.; SCARIANO, M. Uma menina estranha: autobiografia de uma autista. São Paulo: Cia. das letras, 1999.

KANNER, L. Os distúrbios autísticos do contato afetivo. 1943. Disponível em: <http://www.profala.com/artautismo11.htm>. Acesso em: 20 de jun. 2012.

LACADÉE, P. Pour une clinique de l'autisme. Bulletin $d u$ Groupe Petite Enfance, n. 10, p. 47-54, 1997.

LACAN, J. O Seminário: os quatro conceitos fundamentais da psicanálise (1964). Rio de Janeiro: J. Zahar, 1979. livro 11.

LACAN, J. O Seminário: a relação de objeto (1957-1958). Rio de Janeiro: J. Zahar, 1995. livro 4.

LACAN, J. O Seminário: a ética da psicanálise (1959-1960). Rio de Janeiro: J. Zahar, 1997. livro 7.

LACAN, J. O Seminário: de um Outro ao outro (1968-1969). Rio de Janeiro: J. Zahar, 2008. livro 16.

LAURENT, E. Reflexões sobre o autismo. In: . A Sociedade do Sintoma. Rio de Janeiro: Contra Capa, 2007. p. $25-34$

\footnotetext{
${ }^{10} \mathrm{HEMSLEY}$, R. et al. Le traitement des enfants autistes dans environnement familial (1978). In: RUTTER, Michael e SCHOPLER, Eric L'autisme. Une réévaluation du concept et des traitements. Paris: PUF, 1991, 672p.
}

LAURENT, E. O que nos ensinam os autistas. In: MURTA, A.; CALMON, A.; ROSA, M. (Org.). Autismo(s) e atualidade: uma leitura lacaniana. Belo Horizonte: Scriptum, 2012. p. 17-44.

LUCERO, A.; VORCARO, A. Das Ding e o outro na constituição psíquica. Estilos da Clínica, ano XIV, n. 27, p. 230-251, 2009.

MAHLER, M. O nascimento psicológico da criança. Porto Alegre, RS: Artmed, 2002.

MALEVAL, J.-C. Ébauche d'une approche de la spécificité de la psychose autistique. Bulletin du Groupe Petite Enfance, n. 10, p. 136-138, 1997.

MALEVAL, J.-C. Qual o tratamento para o sujeito autista? Revista da Faculdade de Educação da UFG, Goiânia, v. 34, n. 2, p. 405-452, 2009a.

MALEVAL, J.-C. Os objetos autísticos complexos são nocivos. Psicologia em Revista, v. 15, n. 2, p. 223-254, 2009 b.

MALEVAL, J.-C. Língua verbosa, língua factual e frases espontâneas nos autistas. In: MURTA, A.; CALMON, A.; ROSA, M. (Org.). Autismo(s) e atualidade: uma leitura lacaniana. Belo Horizonte: Scriptum, 2012. p. 45-69.

PERRIN, M. Construction d'une dynamique autistique: de l'autogire à la machine à laver. In: MALEVAL, J.-C. (Dir.). L'autiste, son double et ses objets. Rennes, FR: Presses Universitaires de Rennes, 2009. p. 69-100.

PIMENTA, P. R. O objeto autístico e sua função no tratamento psicanalítico do autismo. 2012. Tese (Doutorado)-Faculdade de Filosofia e Ciências Humanas, Universidade Federal de Minas Gerais, Belo Horizonte, 2012.

REY-FLAUD, H. L'enfant qui s'est arrête au seuil du langage. Aubier: Flammarion, 2008

SAFATLE, V. A paixão do negativo. São Paulo: UNESP, 2006.

SAFATLE, V. Lacan. São Paulo: Publifolha, 2007. Coleção Folha Explica.

SAFOUAN, M. O Fracasso do princípio do prazer. Campinas: Papirus, 1988.

SILVESTRE, M. L'autisme infantile. Bulletin du Groupe Petite Enfance, n. 10, p. 9-17, 1997.

SOLER, C. Autisme et paranöia. Bulletin du Groupe Petite Enfance, n. 10, p. 22-30, 1997.

TUSTIN, F. Autismo e Psicose Infantil (1972). Rio de Janeiro: Imago, 1975.

TUSTIN, F. Autistic States in Children. London: Routledge and Kegan Paul, 1981.

WINNICOTT, D. W. Objetos transicionais e fenômenos transicionais (1951). In: de Janeiro: Imago, 1975. p. 13-44 O Brincar \& a Realidade. Rio

Recebido em: 16 de julho de 2012 Aceito em: 25 de setembro de 2015 